\title{
Excretion of tryptophan metabolites in Friedreich's ataxia
}

\author{
N. ROBINSON, G. CURZON, AND P. THEAKER \\ From the Department of Chemical Pathology, the Institute of Neurology, The National Hospital for Nervous \\ Diseases, London
}

SYNOPSIS The overnight urinary excretions of the tryptophan metabolites 5-hydroxy indole acetic acid (5HIAA), indole acetic acid (IAA), indoxyl sulphate, and kynurenine were determined in 10 cases of Friedreich's ataxia and in 11 controls. Levels of 5HIAA and IAA were slightly lower and of indoxyl sulphate higher than in the controls but within normal limits; kynurenine was normal.

A tryptophan load test subsequently given to four patients and three controls showed no significant abnormality in IAA, 5HIAA, indoxyl sulphate, and kynurenine.

A specific abnormality in tryptophan metabolism in Friedreich's ataxia suggested by other workers was not observed.

Indole acetic acid and other tryptophan metabolites are excreted in the urine in grossly increased amounts in Hartnup disease (Baron, Dent, Harris, Hart, and Jepson, 1956) and it has been suggested that indole acetic acid may be related in some way to the intermittent cerebellar ataxia which occurs in this disease (Milne, Crawford, Girão, and Loughridge, 1960). It was therefore of interest when Fischl and Rabiah (1964) found markedly high excretion of indole acetic acid in four subjects with Friedreich's ataxia, especially as Weissbach, King, Sjoerdsma, and Udenfriend (1959) had previously reported high excretion by one subject with this disease. These results suggested that the ataxias occurring in both Friedreich's ataxia and Hartnup disease might be reflected in abnormal urinary excretion patterns of tryptophan metabolites. Therefore, the excretion of indole acetic acid and other tryptophan metabolites by subjects with Friedreich's ataxia and by a control group of subjects was determined. Tryptophan load tests were also performed on some of the subjects.

\section{MATERIAL}

Six patients with Friedreich's ataxia and five controls from one Cheshire Home and four patients and six controls from another Cheshire Home were investigated. Five of the patients with Friedreich's ataxia and five of the control group were male adults and the rest female adults. In the first group of patients two pairs were siblıngs and the second group contained two twin sisters. The controls were patients suffering from Still's disease, degeneration

Received for publication 17 May 1965. of the basal ganglia, paraplegic spasticity, tuberculosis of the spine, congenital athetosis, Parkinson's disease, and multiple sclerosis (three subjects). They were selected as being of approximately the same mobility as the Friedreich's ataxia patients, all being in wheel chairs. All the subjects from each Home were on the same diet from which foods known to produce raised excretion of indolic substances were excluded. None of the subjects with Friedreich's ataxia were on drugs but two patients of the control group were on barbitone and Hexopal. These drugs are not known to influence the urinary excretion of the substances under investigation. Overnight urines of both groups of patients in the same Home were collected on the same date into $3 \mathrm{ml}$. $6 \mathrm{~N} \mathrm{HCl}$ and aliquots stored at $-25^{\circ} \mathrm{C}$. before use.

The tryptophan load tests were made in one Home on four subjects and three controls. Twenty-four-hour urines were collected before and after oral administration of $7 \mathrm{~g}$. L-tryptophan suspended in $100 \mathrm{ml}$. distilled water.

\section{METHODS}

INDOLE ACETIC ACID (IAA) Jepson's (1960) modification of the method of Weissbach et al. (1959) was applied to acid-hydrolysed urines. Estimations therefore represent free plus conjugated IAA.

5-HYDROXY INDOLE ACETIC ACID (5HIAA) This was determined essentially by the method of Todrick, Dick, and Tait (1958) except that optical densities were measured at $520 \mathrm{~m} \mu$ using a $4 \mathrm{~cm}$. light path.

INDOXYL SULPHATE (Is) This was determined by the method of Curzon and Walsh (1962) and is given in terms of the potassium salt. 
KYNURENINE Aliquots of urine containing $0.1 \mathrm{mg}$. creatinine were spotted on to 8 in. sq. sheets of Whatman no. 1 paper and run in n-butanol-acetic acid-water (12:3:5 by volume) and then in the second direction in distilled water according to the method of Coppini, Benassi, and Mortorsi (1959). The kynurenine spot was identified under ultra-violet light, cut out, eluted in $4 \mathrm{ml}$.

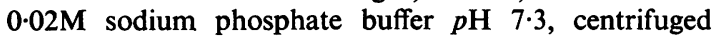
briefly to remove paper fibres, and read at $360 \mathrm{~m} \mu$.

CREATININE A modification of the method of King and Wootton (1956) was used.

\section{RESULTS}

OVERNIGHT URINARY EXCRETION OF TRYPTOPHAN METABOLITES The overnight excretions of IAA, 5HIAA, and IS by patients and controls are shown individually in Figure 1. Amounts are expressed by the ratio metabolite/creatinine, thus correcting for possible differences in urine collection times. There is no gross difference between the excretion of the metabolites by the patients with Friedreich's ataxia and control subjects. Results suggest a slightly lower excretion of IAA and 5HIAA and a higher excretion of IS by the Friedreich's ataxia group than by the control group.

The average excretion of IAA by the Friedreich's ataxia group was $9.36 \mathrm{mg}$. $/ \mathrm{g}$. creatinine which is only slightly higher than an average excretion of $8.07 \mathrm{mg}$. $/ \mathrm{g}$. creatinine for 24-hr. urines of 22 patients in a neurological hospital (Curzon, Gardiner, Walsh, and Cumings, 1963) and not significantly different from $10 \cdot 1 \mathrm{mg}$. IAA/24 hr. reported by Fischl and Rabiah for 36 normal subjects. The average excretion of IAA by the control group was $12.6 \mathrm{mg} . / \mathrm{g}$. creatinine. Thus it is clear that excretion of IAA in Friedreich's ataxia is not elevated in comparison with a group of control subjects with roughly the same degree of locomotor impairment.
Average excretions of 5HIAA were 4.01 and $4.66 \mathrm{mg} . / \mathrm{g}$. creatinine for the Friedreich's ataxia $\stackrel{\overrightarrow{\mathcal{F}}}{\overrightarrow{7}}$ and control subjects respectively and may be com- pared with the excretion of $3.50 \pm 1.72 \mathrm{mg} . / \mathrm{g}$. 등 creatinine for 20 patients in a neurological hospital के (Curzon, 1958).

Average excretions of IS were $52 \cdot 7$ and $35 \cdot 3 \mathrm{mg} . / \mathrm{g}$. creatinine respectively for the Friedreich's ataxia ${ }^{\text {s }}$ and control groups. A group of 28 patients in a $\vec{\circ}$ neurological hospital excreted an average of $44 \overrightarrow{\vec{H}}$ mg./g. creatinine in 24-hr. urines (Curzon and Walsh, $\stackrel{\omega}{\sigma}$ 1962).

TRYPTOPHAN LOAD TEST The effect of $7 \mathrm{~g}$. oral $\vec{\oplus}$ L-tryptophan load upon the excretion of some? tryptophan metabolites by four subjects is shown in $\varphi$ Table I. There is no apparent difference between the 0

TABLE I

URINARY EXCRETION OF TRYPTOPHAN METABOLITES $24 \stackrel{\circ}{\circ}$ HOURS BEFORE AND AFTER ORAL L-TRYPTOPHAN

\begin{tabular}{|c|c|c|c|c|}
\hline th & $\underset{(m g . / 24 h r .)}{I A A .}$ & $\begin{array}{l}\text { SHIAA } \\
(m g . / 24 h r .)\end{array}$ & $\begin{array}{c}I S \\
(m g . / 24 h r .)\end{array}$ & $\begin{array}{c}K Y N \\
(m g . / 24 h r .)\end{array}$ \\
\hline
\end{tabular}

Friedreich's ataxia

1 Before load

After load

2 Before load After load

3 Before load

After load

4 Before load After load

Controls

1 Before load After load

2 Before load

After load

3 Before load

After load

$\quad 9 \cdot 63$
$54 \cdot 4$
$11 \cdot 7$
$27 \cdot 0$
$11 \cdot 3$
$52 \cdot 7$
$26 \cdot 4$
$47 \cdot 8$

$10 \cdot 8$
$47 \cdot 0$
$11 \cdot 6$
$48 \cdot 6$
$20 \cdot 4$
$91 \cdot 5$

$2 \cdot 82$
$4 \cdot 80$
$2 \cdot 33$
$4 \cdot 14$
$3 \cdot 21$
$4 \cdot 48$
3.44
$3 \cdot 87$

3.07
$3 \cdot 53$
3.91
$4 \cdot 05$
$4 \cdot 35$
4.90

$37 \cdot 4$
$35 \cdot 8$
-
$42 \cdot 4$
$42 \cdot 9$
-
-
$69 \cdot 3$
$47 \cdot 5$
-
$\overline{47 \cdot 8}$
$44 \cdot 1$

Friedreich's ataxia and control groups with respect to excretion of IAA. Results are comparable with 3 an average rise of $47 \mathrm{mg}$. IAA after $100 \mathrm{mg} . / \mathrm{kg}$.
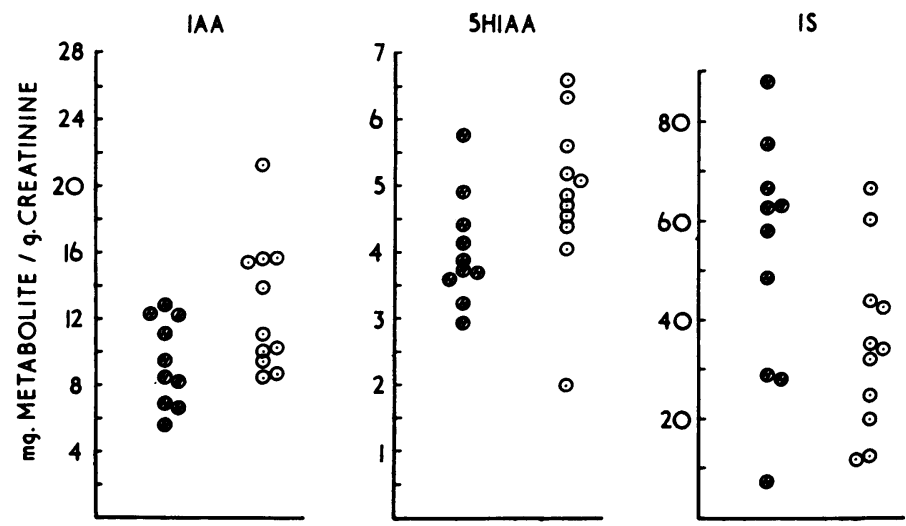

FIG. 1. Overnight urinary excretion of IAA, SHIAA, and IS by subjects with Friedreich's ataxia $(\bigotimes)$ and by a control group $(\odot)$. Amounts are expressed by the ratio: metabolite/creatinine. 
oral L-tryptophan load calculated from the results of Michael, Drummond, Doeden, Anderson, and Good (1964) for a normal group. The rise in 5HIAA excretion after a tryptophan load is higher in the Friedreich's ataxia group than in the control group. This is probably a refiection of the rather higher 5HIAA excretion before a tryptophan load in the small control group used than in the Friedreich's ataxia group since the total excretion of 5HIAA after such a load is similar in both groups. The lack of effect of a tryptophan load on IS excretion is in agreement with the findings of Michael et al. (1964) and indicates that the tryptophan administered was completely absorbed from the upper intestine, IS being derived from bacterial metabolism of tryptophan in the lower part of the gut.

Urinary kynurenine before a tryptophan load was not detectable by the method used. The amounts excreted after loading by both groups are comparable with the average rise of $117 \mathrm{mg}$. calculated from the results of Michael et al. (1964). These workers observed considerable individual variation in the effect of tryptophan loading on kynurenine excretion.

\section{DISCUSSION}

This investigation does not confirm the suggestion by Fischl and Rabiah (1964) that raised IAA excretion in patients with Friedreich's ataxia may represent a specific enzyme defect. In our study patients with Friedreich's ataxia were compared with a group of patients suffering from other diseases but with comparable impaired mobility. Thus it is suggested that the elevated excretion reported by Fischl and Rabiah is probably related to non-specific factors in Friedreich's ataxia. Among these factors may be included the effect of long periods in hospital upon the urinary excretion of substances derived from intestinal bacterial metabolism (Kety, 1959), urinary IAA originating partly from this source.
Also there is probably a relationship between activity and urinary indole acetic acid. Král, Ženíšek, and Stolz (1956) report elevated excretion of IAA following muscular effort. Therefore the finding of high urinary IAA in Friedreich's ataxia by Fischl and Rabiah may be secondarily related to abnormal locomotion by patients with this disease. It may be significant that they also found high IAA levels in muscular dystrophy and that Weissbach et al. (1959) observed high IAA excretion by single subjects with muscular dystrophy and amyotrophic lateral sclerosis.

Furthermore, the results of tryptophan load experiments also provide evidence against a specific abnormality of tryptophan metabolism in Friedreich's ataxia.

We thank Professor J. N. Cumings for his interest in this study. We are also indebted to the matrons of the Cheshire Homes for their valuable help in obtaining the material. We gratefully acknowledge financial support from the Evelyn Staines Fund (N.R.) and from Sandoz Ltd. (P.T.)

\section{REFERENCES}

Baron, D. N., Dent, C. E., Harris, G., Hart, E. W., and Jepson, J. B. (1956). Lancet, 2, 421.

Coppini, D., Benassi, C. A., and Mortorsi, M. (1959). Clin. Chem., $5,391$.

Curzon, G. (1958). Confin. neurol. (Basel), 18, 211.

-, Gardiner, D., Walsh, J., and Cumings, J. N. (1963). Clin. chim. Acta, 8, 255.

_ and Walsh, J. (1962). Ibid., 7, 657.

Fischl, J., and Rabiah, S. (1964). Clin. Chem., 10, 281.

Jepson, J. B. (1960). In Recent Advances in Clinical Pathology, Series 3, p. 177, Churchill, London.

Kety, S. S. (1959). Science, 129, 1528.

King, E. J., and Wootton, I. D. P. (1956). Microanalysis in Medical Biochemistry, 3rd ed., p. 161. Churchill, London.

Král, J. A. Żenísek, A., and Stolz, I. (1956). Biochim. biophys. Acta (Amst.), 19, 169.

Michael, A. F., Drummond, K. N., Doeden, D., Anderson, J. A., and Good, R. A. (1964). J. clin. Invest., 43, 1730.

Milne, M. D., Crawford, M. A., Girão, C. B., and Loughridge, L. W. (1960). Quart. J. Med., 29, 407.

Todrick, A., Dick, M., and Tait, A. C. (1958). Brit. med. J., 1, 496. Weissbach, H., King, W., Sjoerdsma, A., and Udenfriend, S. (1959). J. biol. Chem., 234, 81 . 